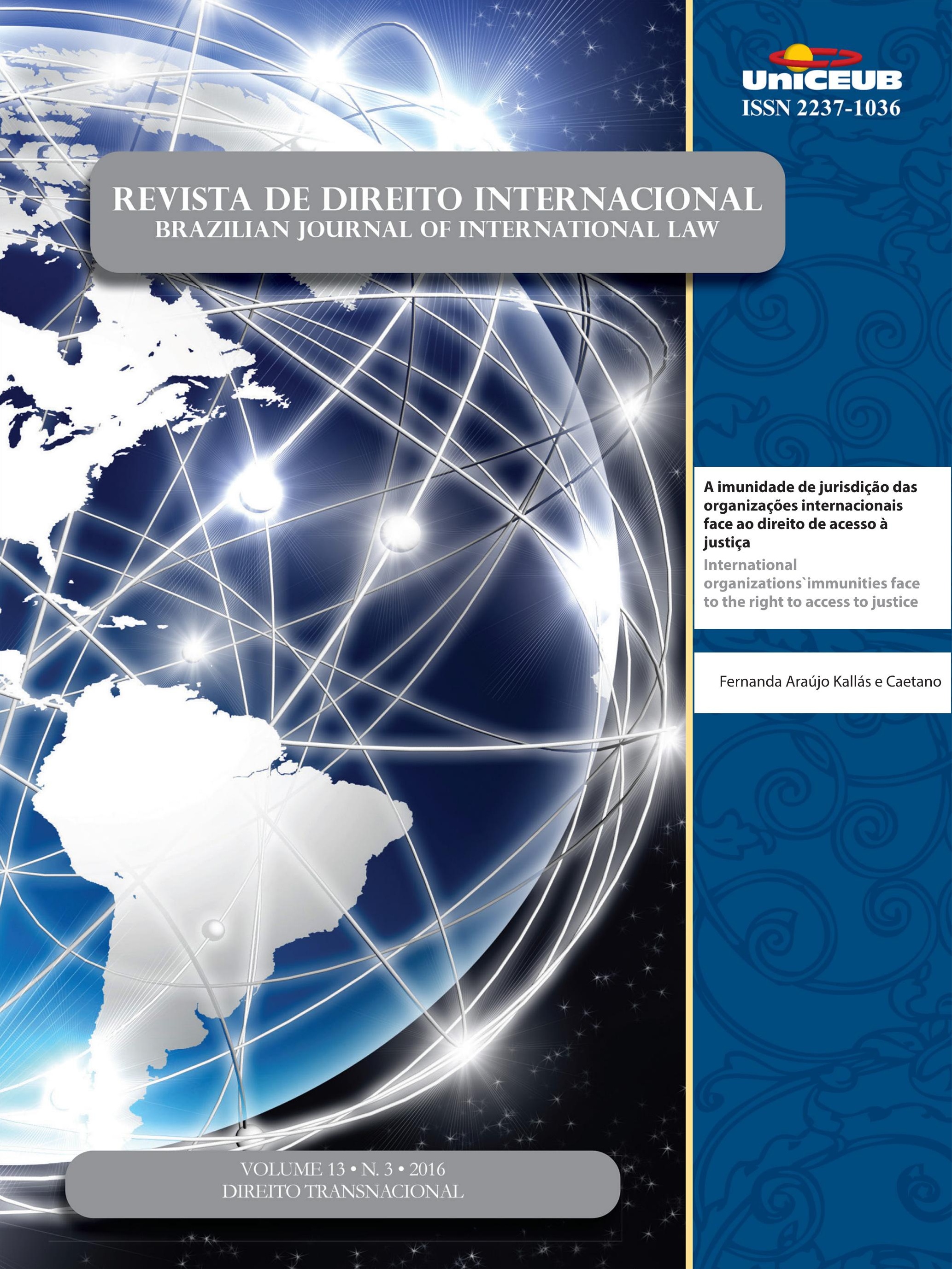


Crônicas da ATUALIdAde do direito internacional .................................................. 2

I. Dossiê Temático: Direito Transnacional .........................................................15

EDITORIAL: O Direito Transnacional - Circulação de normas e relações jurídicas transnacionais .......16 Priscila Pereira de Andrade

A emergênCia do direito transnacional ambiental .............................................18 Priscila Pereira de Andrade

Desafíos y RESPUESTAS TRANSNACIONALES FRENTE A LOS CRÍMENES AMBIENTALES ...............30 Rosmerlin Estupiñan-Silva

DiREITO TRANSNACIONAL E MUdANÇAS CLIMÁTICAS .50 Géraud de Lassus Saint-Geniès

Especies en movimiento: la Convención sobre el Comercio Internacional de Especies Amenazadas de Fauna y Flora Silvestres como espacio de “Encuentro” de discursos, ACTORES Y ESTRATEGIAS EN EL DERECHO AMBIENTAL TRASNACIONAL

María Valeria Berros e Dabel Leandro Franco

El carácter transnacional del Sistema comunitario de ECogestion « Eco-ManageMENT AND Audit SCHEME » (EMAS) DENTRo de LA UE y MÁs ALlÁ DE SUS Fronteras ......72 Adélie Pomade

O CONCEITO DE CONDUTA EMPRESARIAL RESPONSÁVEL À LUZ DOS ORDENAMENTOS JURÍDICOS BRASILEIRO, INTERNACIONAL E TRANSNACIONAL

Gabriel Webber Ziero

ARBITRAGEM NO DIREITO TRIBUTÁRIO INTERNACIONAL E NO DIREITO INTERNACIONAL DOS INVESTIMENTOS: UMA MANIFESTAÇÃO DO DIREITO TRANSNACIONAL

Vivian Daniele Rocha Gabriel 
O DIREITO TRIBUTÁRIO SOB UMA PERSPECTIVA TRANSNACIONAL

Franciele de Simas Estrela Borges

As Características do Direito Transnacional como Metodologia: Análise sob o enfoQue dos Aspectos Processuais da Arbitragem 126

Flávia Foz Mange

O DIREITO TRANSNACIONAL (“GLOBAL LAW") E A CRISE DE PARADIGMA DO ESTADO-CENTRISMO: É POSSÍVEL CONCEBER UMA ORDEM JURÍDICA TRANSNACIONAL? ...................................... 146

Luiza Nogueira Barbosa e Valesca Raizer Borges Moschen

TransPorte AÉREO E DIREITO TRANSNACIONAL: DA CONVERGÊNCIA À UNIFORMIDADE 160 Mickael R. Viglino

Outros Artigos. 175

O Fundo Monetário Internacional e a proteção dos direitos humanos: uma análise DO PROGRAMA DE CRESCIMENTO E REDUÇÃO DA POBREZA NO HAITI 177

Pablo Henrique Hubner de Lanna Costa e Carlos Alberto Simões de Tomaz

Um estranho no ninho? Padrões privados no Acordo de Barreiras Técnicas ao CoMÉRCIO DA OMC 192

Michelle Ratton Sanchez Badin e Marina Yoshimi Takitani

Os benefícios tributários do programa Inovar-Auto e os princípios da Nação Mais Favorecida e do Tratamento Nacional: uma análise dos argumentos dos Painéis atualmente em Curso contra o Brasil no Órgão de SoluÇão de Controvérsias da OMC . 211 Eric Moraes Castro e Silva

A ERA DA HUMANIDADE: REFLEXões PARA A HISTÓRIA DO DIREITO INTERNACIONAL 236 Henrique Weil Afonso

Precedentes vinculantes nos Estados Unidos da América e no direito brasileiro: Um ESTUDO COMPARADO 264

Patrícia Perrone Campos Mello 
IL DIRITTO AMBIENTALE SECONDO L'OTTICA DEL DIRITTO COSTITUZIONALE POSITIVO E LA RESPONSABILITÀ PER DANNI ALL'AMBIENTE NEL DIRITTO COMUNITARIO: LO STATO DELL'ARTE DEL DIRITTO AMBIENTALE COSTITUZIONALE E COMUNITARIO 287

Elcio Nacur Rezende

DA DESCONSIDERAÇÃo DA PERSONALIDADE JURÍDICA NAS RELAÇÕES CONSUMEIRISTAS BRASILEIRAS: ANÁLISE À LUZ DAS TEORIAS CLÁSSICAS

Daniel Amin Ferraz e Marcus Vinicius Silveira de Sá

ANALYSIS OF ADVANTAGES AND DISADVANTAGES OF FORUMS PRESCRIBED UNDER THE UNCLOS AND STATE PRACTICE: THE WAY AHEAD FOR INDIA ......................................................319

Vinai Kumar Singh

Do governo POR LEIS À governanÇA POR NúMERos: breve anÁlise do Trade in SERVICE AgreEMENT (TISA) ...............................................................................338 Jânia Maria Lopes Saldanha, Rafaela da Cruz Mello e Têmis Limberger

As DIRETIVAS EUROPEIAS COMO NORMA REGULADORA DO DIREITO ADMINISTRATIVO GLOBAL ..356 Alice Rocha da Silva e Ruth Maria Pereira dos Santos

O desenVolvimento da POlítica AGRícola COMUM dA UNião EUROPEIA 375 Tatiana de A. F. R. Cardoso Squeff

A imunidade de Jurisdição das organizaÇões internacionais FaCE AO Direito de aCESSO À JUSTIÇA 391

Fernanda Araújo Kallás e Caetano

O DIREITO INTERNACIONAL ENTRE O DEVER ÉTICO E A AÇÃo POLÍ́TICA: OS FUNDAMENTOS DE UM DEVER DE COOPERAÇÃO INTERNACIONAL NA FILOSOFIA POLÍTICA DE IMMANUEL KANT .405 Ademar Junior Pozzatti

EXTENSÃo E FRAGMENTAÇÃo NO CONTEXTO DA JURISDIÇÃO PENAL INTERNACIONAL .423 Marcus Vinícius Xavier de Oliveira

A DEFINiÇÃo JURÍdiCA DA "COMUNIDADE" .444 Nitish Monebhurrun, Michelle Lucas Cardoso Balbino, Fernanda Castelo Branco Araujo, Othon Pantoja, Míara Bogo Bruno e Cândida Dettenborn Nóbrega 
Comparative Study on Chinese Local Legislation of Science and Technology ProGRESS

LI Xiaoming e LI Yihan

O CONTROLE PENAL DO TRÁFICO DE PESSOAS: CONSTRUÇÃO JURÍDICA, INTERAÇÕES ORGANIZACIONAIS E COOPERAÇÃO INTERNACIONAL

Bruno Amaral Machado e Priscilla Brito Silva Vieira

Desativismo judicial: a extradição Battisti no Supremo Tribunal Federal .505 Francisco Rezek e Israel Paulino

A decisão norte-americana do Caso Myriad: novos paradigmas para a Proteção patenTÁRIA DO CÓDIGO GENÉTICO HUMANO E BIOTECNOLOGIA 514 José Carlos Vaz e Dias e Clarisse De La Cerda 


\title{
A imunidade de jurisdição das organizações internacionais face ao direito de acesso à justiça*
}

\author{
International organizations immunities face \\ to the right to access to justice
}

Fernanda Araújo Kallás e Caetano**

\section{Resumo}

O presente artigo objetiva analisar a possibilidade de relativização das imunidades de jurisdição e de execução das organizações internacionais sob o argumento da ocorrência de uma afronta ao direito de acesso à justiça. Para tanto, utiliza-se de fontes bibliográficas e jurisprudenciais. Primeiramente, reconhecemos que a imunidade por si só não contraria o direito de acesso à justiça na medida em que ela não pretende privar o requerente de toda possibilidade de ver sua causa processada, mas, apenas, indicar que o foro escolhido é inadequado, direcionando-o a outro foro mais apropriado para o julgamento da demanda. Em seguida, partimos para a análise da possibilidade de relativização da regra da imunidade nos casos em que a organização internacional não tenha indicado vias alternativas efetivas para a solução das controvérsias. Finalmente, foi colocada em questão a relativização da imunidade da organização internacional pelas cortes de um Estado que dela seja membro. Concluímos que, apesar de a imunidade dever ser relativizada nos casos em que a organização internacional não tenha apresentado outras vias de recurso para a solução do litígio, tal medida não poderia ser tomada quando o Estado do foro venha ser dela parte pois, como membro do sistema, ele não poderia se considerar estranho a essa responsabilidade. Em tais situações, o Estado do foro deveria manter as imunidades da organização da qual é membro, arcando com o ônus que a priori seria da organização, a fim de conciliar o direito de acesso à justiça do particular com as obrigações estatais resultantes da lógica organizacional.

Palavras-chave: Imunidades de jurisdição. Imunidades de execução. Imunidades relativas. Organizações internacionais. Acesso à justiça.

* Recebido em 09/09/2016

Aprovado em 24/11/2016

** Doutora em Direito Internacional pela PUC-MG (2016). Mestre em Direito Internacional pela Université Paris II (2006), diploma revalidado no Brasil pela UnB (2007). Professora de Direito Internacional Público e Direito Internacional Privado do Centro Universitário Una, do Centro Universitário de Belo Horizonte - UniBH e da Faculdade Promove. Professora do Curso de Pós-Graduação em Direito Internacional do Cedin-BH. Pesquisadora do grupo de pesquisa Empresa, Mercado e Desenvolvimento Social (UNA). Advogada. E-mail: fernanda@kallasecaetano.com.br.

\section{Abstract}

This paper aims to analyse the legal framework of international organizations' immunities of jurisdiction and of enforcement and the possibility of relativization of these immunities on the grounds of the occurrence of an affront to the right to access to justice. The study is based on bibliographic and jurisprudential sources. Firstly, we admit that the immunity by itself does not affect the right of access to justice to the extent that it does not intend to deprive the applicant of every possibility of pursuing a judi- 
cial solution, but only intend to indicate that the chosen forum is inappropriate, directing the applicant to another forum more appropriate for the trial of the action. Then, we proceed to analyse the possibility of relativizing the immunity rule in cases where the international organization has not indicated effective alternative means for settlement of disputes. Finally, the relativisation of the immunity of the international organization by the courts of a State that is a member was questioned. We conclude that, although immunity should be relativized in cases where the international organization has not lodged other remedies for the settlement of the dispute, such a measure could not be taken by the State of the forum which is its party because, as a member of the system, it could not be considered unrelated to that responsibility. In such situation, the forum State should keep immunities of the Organization, bearing the burden that would be a priori of the organization itself, in order to reconcile the right of access to justice from the perspective of the private part to state obligations under the organizational logic.

Keywords: Immunities of jurisdiction. Immunities of enforcement. Relative Immunities. International organizations. Access to justice.

\section{INTRODUÇÃo}

O exercício da jurisdição figura dentre os direitos básicos do Estado. Ele tem por pressuposto que todas as pessoas e bens situados no território estatal se encontrem submetidos às leis e tribunais do Estado. Todavia, esse direito sofre limitações quando os Estados decidem viver em comunidade. Assim, as relações interestatais, como qualquer outro tipo de interação, requerem concessões e esforços. Uma dessas concessões diz respeito ao direito das imunidades. Elas são, desse ponto de vista, conjectura fundamental da manutenção das relações diplomáticas e da própria coexistência da comunidade internacional.

Conforme a máxima par in parem non habet judicium, as pessoas jurídicas internacionais de igual posição não podem exercer jurisdição umas sobre as outras, ou seja, nenhum Estado soberano pode ser submetido à condição de parte perante o foro doméstico de outro Estado contra a sua vontade. ${ }^{1}$ Assim, ao impedir que os tribunais internos de um país julguem ações concernentes à soberania de um ente público externo, garante-se a não ingerência nos assuntos internos dos Estados estrangeiros. Dessa forma, a imunidade de jurisdição constitui, ao mesmo tempo, uma proteção à soberania de um Estado, que se vê protegido da possibilidade de ser subordinado a outra jurisdição que não a sua própria e uma limitação à soberania de outro, que se encontra impossibilitado de exercer jurisdição plena em seu território. ${ }^{2}$

A lógica de garantia das imunidades foi estendida aos outros sujeitos incontestáveis do direito internacional público, quais sejam, as organizações internacionais. Tais entidades, formadas pela reunião de Estados soberanos, possuem titularidade de direitos e deveres internacionais. Contudo, no caso das organizações internacionais, não há que se falar no elemento soberania. A justificativa para a concessão do privilégio é a necessidade de independência da organização internacional para a realização das funções previstas em seu tratado constitutivo, visando afastar a ingerência dos governos por meio da aplicação de seu direito interno.

Ao contrário das imunidades dos Estados estrangeiros, que são uma construção costumeira, os privilégios e imunidades das organizações internacionais estão, normalmente, previstos em três tipos de tratados: os tratados constitutivos, as convenções multilaterais e os acordos bilaterais de sede. Na maior parte dos casos, tais instrumentos dispõem sobre a imunidade das organizações internacionais em termos absolutos - como é o caso da Convenção sobre Privilégios e Imunidades das Agências Especializadas da Organização das Nações Unidas ${ }^{3}$. Há, evidentemente, algumas exceções como, por exemplo, o Acordo de Sede firmado pelo Brasil com a União Latina ${ }^{4}$, bem como o Acordo de

1 REZEK, Francisco. Direito Internacional Público: Curso Elementar. São Paulo: Saraiva, 2010.

2 ABREU, Patrícia Maria Lara; RAPOSO, Rodrigo Otávio Bastos Silva. Imunidade de jurisdição do Estado e reparação civil pela prática de tortura: o caso Zahra Kazemi v. República Islâmica do Irã. Revista de Direito Internacional, Brasília, v. 11, n. 2, p. 412-434, 2014, p.422-423.

3 Ver Seção 4 do Art. 3 da Convenção sobre Privilégios e Imunidades das Agências Especializadas da Organização das Nações Unidas, promulgada pelo Decreto $n^{\circ} 52.288 / 63$.

4 Ver art. $3^{\circ}$ do Acordo entre o Governo da República Federativa do Brasil e a União Latina Relativo ao Estabelecimento, no Rio de Janeiro, de um Escritório e de seus Privilégios e Imunidades no Território Brasileiro. Paris, 15 abr. 1999, promulgado no Brasil pelo Decreto 4.099, de 23.1.2002. 
Sede firmado entre o Brasil e a Organização dos Estados Ibero-Americanos para a Educação, a Ciência e a Cultura (OEI), ${ }^{5}$ em que se estipulou a imunidade restrita das respectivas organizações por meio de exceções em casos de ações decorrentes de acidentes ou infrações de trânsito, ações trabalhistas, ações cíveis decorrentes de atos contratuais e atividades comerciais da organização.

Contudo, quando a imunidade absoluta das organizações internacionais é uma disposição convencional, ela não é alcançada pela costumeira distinção entre atos jus imperii e atos jus gestionis trazida ao conhecimento da doutrina nacional em 1989 por meio do célebre voto do Ministro Francisco Rezek na Apelação Cível 9.969-3/ $\mathrm{SP}^{6}$, que excluiu o benefício da imunidade aos Estados estrangeiros pela prática de atos de gestão.

Ocorre que, com a proliferação das organizações internacionais, houve um aumento significativo do número de particulares que com elas mantêm relações. Essas relações englobam desde o fornecimento de mercadorias, locação de imóveis e questões resultantes de acidentes de trânsito até a prestação de serviços diversos e as relações de emprego com esses entes. Frente a essa situação, a tradicional previsão normativa da imunidade ilimitada das organizações passou a atingir um número cada vez maior de pessoas, tanto físicas quanto jurídicas.

Diante disso, a questão que este artigo pretende abordar é a de saber quando seria possível relativizar as imunidades dessas organizações, mesmo nos casos em que exista previsão convencional que disponha sobre a imunidade absoluta de tais entes, sob o argumento da ocorrência de uma afronta ao direito de acesso à justiça.

\section{A haRMONIZAÇÃo ENTRE A IMUNIDADE DAS ORGANIZAÇÕES INTERNACIONAIS E O DIREITO DE ACESSO À JUSTIÇA}

Há quem defenda que a regra da imunidade de jurisdição das organizações internacionais fragilizaria a

\footnotetext{
5 Ver art. $9^{\circ}$ do Acordo de Sede entre o Governo da República Federativa do Brasil e a Organização dos Estados Ibero-Americanos para a Educação, a Ciência e a Cultura (OEI). Brasília, 30 jan, 2002, promulgado no Brasil pelo Decreto n. 5.128, de 6 de julho de 2004. 6 Ver BRASIL. Supremo Tribunal Federal. Apelação Cível n. 9.696-3-SP. Relator: Sydnei Sanches. Diário de Justiça. Brasília, 31 maio 1989. Voto do Ministro Francisco Rezek.
}

garantia de acesso à justiça ${ }^{7}$, constituindo um obstáculo processual que teria como consequência a extinção da ação sem julgamento do mérito, ou seja, sem que qualquer decisão acerca da responsabilidade seja proferida. Isso impediria que o particular pudesse se valer de um recurso efetivo perante as autoridades competentes locais contra tais entes do direito internacional.

Tal questão foi invocada por diversas vezes perante a Corte Europeia de Direitos Humanos, sob os auspícios do artigo $6^{\circ}, \$ 1^{o 8}$, da Convenção Europeia. Como a vasta jurisprudência resultante da aplicação desse dispositivo havia estabelecido que os particulares possuem o "direito a um tribunal"" independentemente do status do réu, a invocação desse artigo fundamentou uma série de demandas contrárias ao direito das imunidades.

Além disso, nos últimos anos, parte da doutrina vem defendendo a relativização do direito das imunidades nos casos em que os entes de direito internacional tenham agido em desconformidade com as normas jus cogens. No caso das organizações internacionais, esse conceito poderia alcançar questões relacionadas à primazia da norma mais benéfica ao trabalhador e à máxima efetividade ${ }^{10}$ dos direitos sociais. Este, contudo, não é o escopo deste artigo. Tal como determinado pela Corte Internacional de Justiça na sentença proferida no caso Imunidades jurisdicionais do Estado ${ }^{11}$, não entendemos existir conflito entre a imunidade e as normas jus cogens ${ }^{12}$.

7 A discussão sobre a imunidade envolve a análise da ofensa ao direito de acesso à justiça em seu sentido mais restrito, como o direito de acesso a um tribunal.

8 Art. $6^{\circ}$. Direito a um processo equitativo. 1. Qualquer pessoa tem direito a que sua causa seja examinada, equitativa e publicamente, num prazo razoável por um tribunal independente e imparcial, estabelecido pela lei, o qual decidirá, quer sobre a determinação dos seus direitos e obrigações de carácter civil, quer sobre o fundamento de qualquer acusação em matéria penal dirigida contra ela. 9 Ver CORTE EUROPEIA DE DIREITOS HUMANOS. Golder c. Royaume-Uni. Estrasburgo, 21 fev. 1975; CORTE EUROPEIA DE DIREITOS HUMANOS. Osman c. Royaume-Uni. Estrasburgo, 28 out. 1998.

10 Nas lições de Canotilho, conforme o princípio da máxima efetividade, no caso de dúvidas deve preferir-se a interpretação que reconheça maior eficácia aos direitos fundamentais. CANOTILHO, José Joaquim Gomes. Direito Constitucional, 7a edição, Coimbra: Almedina, p. 1224.

11 Ver CORTE INTERNACIONAL DE JUSTIÇA. Immunités juridictionnelles de l'État (Allemagne c. Italie; Grèce (intervenant)). A Haia, 3 fev. 2012.

12 Dentro dessa mesma perspectiva, vide ABREU, Patrícia Maria Lara; RAPOSO, Rodrigo Otávio Bastos Silva. Imunidade de jurisdição do Estado e reparação civil pela prática de tortura: o caso Zahra Kazemi v. República Islâmica do Irã. Revista de Direito Internacional, Brasília, v. 11, n. 2, p. 412-434, 2014. 
Para a Corte, enquanto a regra da imunidade opera na seara processual, a regra de jus cogens é uma regra material. Dessa forma, ao abster-se de julgar a demanda em nome do respeito à imunidade jurisdicional de uma organização internacional, a jurisdição interna não indeferiria o pedido em desrespeito à norma de direito material jus cogens existente. Ao contrário, ela estaria compatibilizando ambas as regras, na certeza de que, apesar de ter-se abstido de julgar o litígio, haveria outro foro mais conveniente para o julgamento da ação indicado pela organização internacional em questão. Assim, sob essa ótica, só haveria a possibilidade de relativização da regra das imunidades nos casos de inexistência de foro alternativo possível para a resolução da controvérsia, o que teria por consequência a flagrante violação do direito de acesso à justiça.

Dessa forma, a extinção de uma ação sem julgamento do mérito fundamentada na imunidade de jurisdição da organização internacional não tem o condão de impedir qualquer ação judiciária. Ela pode, apenas, impedir, provisoriamente, o juiz estrangeiro chamado a julgar a causa de exercer sua função. Assim, ela não contraria o direito fundamental de acesso à justiça, uma vez que a imunidade não pretende privar o requerente de toda possibilidade de ver sua causa processada, mas apenas indica que o foro escolhido é inadequado. ${ }^{13}$

Uma série decisões tanto da Corte Europeia corroboram a tese de que a disponibilidade de um foro alternativo é fundamental na decisão de conceder ou denegar a imunidade. Trata-se de uma saudável evolução, que tem como propósito assegurar o acesso à justiça enquanto preserva a independência tanto dos Estados estrangeiros quanto das organizações internacionais. ${ }^{14}$

Em duas decisões proferidas em 18 de fevereiro de 1999, referente aos casos Waite and Kennedy e Beer and Regan, a Corte Europeia de Direitos Humanos considerou que o caráter proporcional do limite ao "direito a um tribunal" dependia da certificação da existência de outras vias razoáveis para a proteção eficaz dos direitos

13 Ver WATT, Horatia Muir. Une perspective "internationalisteprivatiste". In: VERHOEVEN, Joe (Org.) Le droit international des immunités: contestation ou consolidation? Bruxelles: Larcier, 2004, p. 266.

14 REINISCH, August; WEBER, Ulf Andreas. In the Shawdow of Waite and Kennedy: The Jurisdicional Immunity of International Organizations: The Individual's Right of Acces to the Courts and Administrative Tribunals as Alternative Means of Dispute Settlement. International Organization Law Review, Leiden, v. 1, n. 1, p. 59-110, 2004, p. 72-73. garantidos pela Convenção. ${ }^{15}$ Nesse sentido, para a Corte, o reconhecimento da imunidade de uma organização internacional só viola o artigo $6^{\circ}, \$ 1^{\circ}$, da Convenção Europeia de Direitos Humanos quando inexistirem outros meios para a solução da controvérsia. É imprescindível, portanto, a comprovação da existência de outras vias para a resolução do litígio.

No caso Waite and Kennedy c. Alemanha a Agência Espacial Europeia havia instaurado uma comissão independente de recursos para conhecer dos litígios interpostos por seus funcionários contra a própria organização, qual seja, a Câmara de Apelação da Agência Espacial Europeia (ESA Appeals Board). A existência dessa comissão teve o condão de afastar o argumento de denegação do direito de acesso à justiça. Dessa ótica, uma organização internacional que indicasse uma forma de recurso jurisdicional apresentando garantias de imparcialidade e de equidade responderia às exigências de ordem pública internacional, podendo reivindicar o benefício de sua imunidade de jurisdição.

A própria Organização das Nações Unidas, em dois estudos realizados em 1967 e 1985, apontou a criação de meios alternativos de solução de controvérsias como uma forma de impedir que a sua imunidade violasse o direito à jurisdição. ${ }^{16}$ Esta foi, inclusive, uma das razões que levaram algumas organizações internacionais a estabelecerem seus próprios mecanismos de solução de controvérsias, com o intuito de evitar que os tribunais nacionais fossem induzidos a assumir a jurisdição se elas viessem a se instaurar. ${ }^{17}$

15 CORTE EUROPEIA DE DIREITOS HUMANOS. Beer e Regan c. Allemagne, Estrasburgo, 18 fev. 1999, \$58; CORTE EUROPEIA DE DIREITOS HUMANOS. Waite et Kennedy c. Allemagne, Estrasburgo, 18 fev. 1999, \$68. "Eu égard en particulier aux autres voies de droit qui s'offraient aux requérants, on se saurait dire que les restrictions de l'accès qux jurisdictions allemandes pour régler le différend des intéressés avec l'ASE aient porte atteinte à la substance même de leur "droit à um tribunal" ou qu'elles aient été disproportionnées sous l'angle de l'article $6 \$ 1 \mathrm{er}$, de la convention". 16 GERSTER, Michael; ROTENBERG, Dirk. Article 105. In: SIMMA, Bruno; KHAN, Daniel-Esrasmus (Orgs.). The Charter of the United Nations: A Commentary. Oxford: Oxford University Press, 1995 , p. 1.140.

17 WELLENS, Karel. Remedies Against International Organisations: Basic Issues. Cambridge: Cambridge University Press, 2002, p. 81-82. 


\section{RELATIVIZAÇÃO DA IMUNIDADE DAS ORGANIZAÇÕES INTERNACIONAIS NA FALTA DE VIAS ALTERNATIVAS EFETIVAS PARA A SOLUÇÃO DAS CONTROVÉRSIAS}

O direito do particular a um juiz não implica o direito de escolher livremente a autoridade perante a qual ele queira se dirigir para julgamento do litígio. Da mesma forma, cabe a cada Estado determinar a competência de seus juízes e aos particulares observarem a disposição legal, sem que possam colocar em questão a opção legislativa, a imunidade de jurisdição obriga o particular a postular a ação em outro lugar, diferente daquele $a$ priori pretendido, o que não significa que por isso venha lhe ser afastado o direito de acesso à justiça.

Utilizando as palavras de Verhoeven,

o importante é, basicamente, que o requerente tenha um acesso (razoável) à justiça e que o processo seja equitativo. Isso não significa que ele pode introduzir uma demanda perante qualquer juiz de sua escolha, em violação às regras do direito interno ou do direito internacional que lhe proíbam de assim agir.

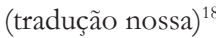

Todavia, quando a imunidade resulta, concretamente, em livrar uma pessoa de toda e qualquer possibilidade de julgamento, ela acarreta de facto a impunidade. Assim, como bem defende Verhoeven, quando a imunidade tiver por efeito a privação do demandante do "único" juiz ao qual ele poderia ter acesso, ela deverá ser relativizada, podendo ser mantida nas demais situações:

no entanto, a imunidade deveria ser descartada se ela tivesse o efeito de privá-lo do "único" juiz ao qual ele possa ter acesso. Nós não entendemos que o direito fundamental de todo o "homem" poder demandar frente à um juiz para obter um julgamento justo deva ser totalmente sacrificado em respeito às imunidades (tradução nossa). ${ }^{19}$

18 «(...) L'important est fondamentalement que le demandeur ait um accès (raisonnable) à la justice, et que le procès soit équitable. Ce n'est pas qu'il puísse saisir tout juge de son choix, au mépris des règles du droit judiciaire national ou du droit international qui le lui interdirait». VERHOEVEN, Joe. Sur les relations entre immunités et "jus cogens", à la lumière de l'arrêt Allemagne-Italie du février 2012. In: Unité et diversité du droit international: écrits en l'honneur du professeur Pierre-Marie Dupuy. Bruxelles: Martinus Nijhoff Publishers, 2014, p. 532.

19 "Cela dit, l'immunité devrait sans doute être écartée si elle avait pour effet de priver celui-ci du "seul" juge auquel il puisse avoir accès. On ne voit pas en effet que le droit fondamental de tout "homme" à pouvoir s'adresser à un juge de manière à obtenir un procès équitable soit totalement sacrifié au respect du à l'immunité". VERHOEVEN, Joe. Considérations sur ce qui est commun: cour

\subsection{A relativização da imunidade de jurisdição}

Seguindo a lógica da Corte Europeia de Direitos Humanos de que a imunidade só seria uma limitação válida ao direito de acesso à justiça se comprovada a existência de outras vias de recurso interno para a solução das controvérsias, a Corte de Cassação francesa entendeu que, quando a imunidade de jurisdição tem por consequência a privação do demandante de qualquer possibilidade de agir em justiça contra uma organização internacional, ela pode ser afastada para evitar o risco de denegação de justiça.

A decisão da jurisdição francesa, proferida em 7 de outubro de 2003, tratava de um litígio envolvendo o Banco Africano de Desenvolvimento e um antigo empregado. Nesse caso, a organização internacional que arguia a sua imunidade não havia previsto em seu Estatuto qualquer tribunal competente para julgar litígios dessa natureza, razão pela qual o benefício da imunidade de jurisdição não pôde ser mantido.

Além do fato de um grande número de organizações internacionais não disponibilizarem mecanismos alternativos de solução de controvérsias nem mesmo a seus empregados e de outras atenderem, apenas, as lides laborais, deixando diversas lides fora da sua competência, há, ainda, aquelas que disponibilizam mecanismos pouco efetivos para a solução das controvérsias.

Ora, para, efetivamente, contrabalançarem a imunidade, os mecanismos de solução de controvérsias devem oferecer garantias de independência e imparcialidade comparáveis àquelas de que os demandantes se beneficiariam se pudessem ter se dirigido aos tribunais estatais. $^{20}$

A grande diferença é que a organização internacional, normalmente, não dispõe de um Poder Judiciário comparável àquele em que se exprime a soberania que caracteriza toda entidade estatal. Assim, são vários os fatores que podem atentar contra a independência e a imparcialidade dos tribunais administrativos.

Primeiramente, é criticável a forma de nomeação de seus juízes. $\mathrm{Na}$ maioria das vezes, são os altos funcionários da organização que são escolhidos para cumprir

général de droit international public. Recueil des cours, A Haia, v. 334, p. 9-434, 2008, p. 315.

20 SILVEIRA, Rubens Curado. A Imunidade de Jurisdição dos Organismos Internacionais e os Direitos Humanos. São Paulo: LTr, 2007 , p. 120 
tal função. Estes, por sua vez, podem estar mais preocupados em proteger os fundos da organização do que necessariamente em determinar uma sanção justa em caso de irregularidades. ${ }^{21}$

Para Gaillard e Pingel-Lenuzza, a intervenção de uma autoridade externa no processo de seleção dos juízes, tal como se dá na Corte Internacional de Justiça e na Corte Europeia de Direitos Humanos, ofereceria maior garantia de independência e legitimidade para os tribunais administrativos das organizações internacionais. $^{22}$

Outro fator que atenta contra a imparcialidade e independência dos tribunais administrativos é a sua dependência financeira das organizações. Pode-se, por fim, criticar a irrecorribilidade das sentenças dos tribunais administrativos, o que, de certa forma, impede que a justiça seja depurada.

Diante disso, deve existir uma preocupação por parte dos tribunais estatais no momento de decidir sobre a manutenção das imunidades das organizações internacionais, posto que a mera existência de meios alternativos não pode justificá-la. Cabe aos tribunais estatais verificar se esses mecanismos atendem, razoavelmente, às garantias mínimas do direito à jurisdição, tais como a independência e a imparcialidade, sob pena de esses mecanismos servirem de mero subterfúgio à perpetuação do privilégio das organizações. ${ }^{23}$

\subsection{A relativização da imunidade de execução}

Para além da concepção tradicional do direito de acesso à justiça que engloba a necessidade de um procedimento judicial - justo e público - e uma organização judiciária - qual seja, um tribunal competente, independente e imparcial, vem sendo cada vez mais invocada a necessidade de efetividade das decisões proferidas.

Nessa esteira, a Corte de Apelação de Bruxelas, em

21 GAILLARD, Emmanuel; PINGEL-LENUZZA, Isabelle. International Organisations and Immunity from Jurisdiction: To Restrict or to Bypass. International and Comparative Law Quarterly, Oxford, v. 51, n. 1, p. 1-15, jan. 2002, p. 11-12.

22 GAILLARD, Emmanuel; PINGEL-LENUZZA, Isabelle. International Organisations and Immunity from Jurisdiction: To Restrict or to Bypass. International and Comparative Law Quarterly, Oxford, v. 51, n. 1, p. 1-15, jan. 2002, p. 12.

23 SILVEIRA, Rubens Curado. A Imunidade de Jurisdição dos Organismos Internacionais e os Direitos Humanos. São Paulo: LTr, 2007, p. 167. uma decisão de 4 de março de 2003, transpôs para a esfera executória o entendimento que havia sido consagrado pela Corte Europeia de Direitos Humanos, no caso Waite e Kennedy c. Alemanha, ${ }^{24}$ de que a imunidade de jurisdição implicaria ofensa ao direito à jurisdição se a parte não tivesse ao seu dispor outro meio adequado para a solução da controvérsia. Sob essa ótica, a Corte belga construiu um raciocínio afirmando que a imunidade (agora de execução) só seria admissível se houvesse outros mecanismos capazes de conduzir à efetivação da res judicata, sob pena de ferir o direito universal à jurisdição.

Essa decisão foi a primeira a afastar a imunidade de execução de uma organização internacional, qual seja, o Secretariado do Grupo de Estados da África, do Caribe e do Pacífico (ACP), sediado em Bruxelas, em um litígio interposto por um empregado demitido que requeria o pagamento dos salários atrasados. A Corte de Apelação belga não se vinculou, no caso, ao acordo de sede, que conduziria à aplicação da imunidade, mas confrontou-o com o que ela considerou serem exigências da Convenção Europeia de Direitos Humanos, preferindo fazer prevalecer esta sobre aquela. Assim, na falta de um modo alternativo de resolução da controvérsia, como a arbitragem ou o recurso a um tribunal especializado, a imunidade de execução da organização foi afastada. Diante disso, a decisão, fundamentada no artigo $6^{\circ}, \$ 1^{\circ}$, da Convenção, entendeu que a execução de uma sentença faz parte integrante do julgamento justo na acepção da Convenção.

Esse raciocínio não deixa de ser audacioso. Contudo, a Corte belga ressaltou que ele só é possível em hipóteses como no caso em questão, em que a resolução do litígio - isto é, o pagamento dos salários em atraso - não prejudique o bom funcionamento da instituição em débito.

Verhoeven comunga do mesmo entendimento. Para ele, a imunidade de execução deve ser afastada quando o particular não dispõe de meios razoáveis para obter, se necessário, a execução forçada do julgamento que foi favorável à sua demanda. O direito humano de acesso à justiça, que envolve a ideia de "processo equitativo", não é menos cogente que àquele da organização internacional de não ser abusivamente obstada na realização de suas funções e de seu objeto social. ${ }^{25}$

24 CORTE EUROPEIA DE DIREITOS HUMANOS. Waite et Kennedy c. Allemagne, Estrasburgo, 18 fev. 1999.

25 VERHOEVEN, Joe. Immunités de Jurisdiction ou d'éxécution, 
Vale lembrar que, apesar de a arbitragem, também, vir sendo sido utilizada como mecanismo alternativo disponibilizado pelas organizações internacionais para a solução das controvérsias, a jurisdição arbitral não possui meios próprios para promover uma execução forçada da decisão proferida, competindo ao Poder Judiciário estatal suprir essa deficiência praticando uma interferência residual. Assim, impedir a execução da sentença arbitral em respeito à inviolabilidade dos bens da organização inadimplente seria negar uma das garantias inerentes ao direito à jurisdição, qual seja, a efetividade do provimento de mérito.

A respeito do tema, Silveira ousa sugerir um mecanismo que possa, efetivamente, conciliar os direitos em colisão, a saber, de um lado o direito à imunidade e de outro o direito à jurisdição. Para o autor, elaborados os cálculos, a organização internacional seria notificada sobre o prazo para o pagamento da dívida. Decorrido o prazo sem a quitação da dívida, seria autorizada a execução forçada, uma vez que a omissão impediria toda e qualquer possibilidade de efetivação do direito reconhecido, ensejando uma denegação de justiça. ${ }^{26}$ Silveira não desconhece, contudo, que, nesse caso, persistiria a impossibilidade de entrada sem autorização nas repartições das organizações internacionais, razão que faria com que a maior parte das constrições fossem direcionadas aos bens externos, tais como das contas bancárias e dos veículos da organização. ${ }^{27}$

\section{ManUtenção das imunidades das ORGANIZAÇÕES INTERNACIONAIS DAS QUAIS O ESTADO DO FORO É MEMBRO, MESMO DIANTE DA AUSÊNCIA DE VIAS ALTERNATIVAS PARA A SOLUÇÃO DE CONTROVÉRSIAS}

Em 25 de outubro de 2005, por meio de um acórdão do Tribunal Pleno do TRT, adotado por maioria

alternatives raisonnables et jurisprudence belge. In: KOHEN, Marcelo Gustavo; KOLB, Robert; DOMINICÉ, Christian (Orgs.). Perspectives du droit international au 21e siècle: Liber amicorum Professor Christian Dominicé. Leiden: Nijhoff, 2012, p. 150-151.

26 SILVEIRA, Rubens Curado. A Imunidade de Jurisdição dos Organismos Internacionais e os Direitos Humanos. São Paulo: LTr, 2007, p. 157.

27 SILVEIRA, Rubens Curado. A Imunidade de Jurisdição dos Organismos Internacionais e os Direitos Humanos. São Paulo: LTr, 2007, p. 158 absoluta dos votos, foi adotada a tese que condicionaria o reconhecimento da imunidade à disponibilização de meios alternativos de solução de controvérsias. Segundo o verbete $17 / 2005$ :

IMUNIDADE DE JURISDIÇÃO.
ORGANISMO INTERNACIONAL. MATÉRIA
TRABALHISTA. INEXISTENCIA. PRINCÍPIO
DA RECIPROCIDADE. Em respeito ao princípio
da reciprocidade, não há imunidade de jurisdição
para Organismo Internacional, em processo de
conhecimento trabalhista, quando este ente não
promove a adoção de meios adequados para
solução das controvérsias resultantes dos contratos
com particulares, nos exatos termos da obrigação
imposta pelo art. VIII, Seção 29, da Convenção de
Privilégios e Imunidades das Nações Unidas.

A aplicação desse entendimento não foi condicionada à natureza do ato em questão, afastando a imunidade das organizações internacionais, ainda, nos casos em que o ato foi praticado no estrito cumprimento de função oficial da organização internacional. O fundamento desse afastamento consiste no fato de que o princípio da reciprocidade, garantido pelo direito internacional, autorizaria o não cumprimento de uma cláusula convencional quando a outra parte não honrasse a obrigação equivalente. ${ }^{28}$

Segundo a Convenção sobre Privilégios e Imunidades das Nações Unidas, em seu artigo VIII, seção 29, a ONU deverá estabelecer "processos adequados de solução" para "as controvérsias em matéria de contratos ou outras de direito privado nas quais a Organização seja parte". Da mesma forma, o art. $9^{\circ}$ da Convenção sobre Privilégios e Imunidades das Agências Especializadas das Nações Unidas dispõe que esses organismos devem providenciar modos apropriados de resolver as "disputas resultantes de contratos ou outras disputas de caráter privado nas quais a agência especializada seja parte". ${ }^{29}$

Para Silveira, por esses tratados, os Estados-membros se comprometeriam, por um lado, a garantir a imu-

28 SILVEIRA, Rubens Curado. A Imunidade de Jurisdição dos Organismos Internacionais e os Direitos Humanos. São Paulo: LTr, 2007, p. 105.

29 ORGANIZAÇÃO DAS NAÇÕES UNIDAS. Convenção sobre Privilégios e Imunidades das Agências Especializadas. Nova Iorque, 2 dez. 2004. Art. 9 - Solução de disputas. 31 a Seção - Cada agência especializada providenciará modos apropriados de resolver: a) disputas resultantes de contratos ou outras disputas de caráter privado nas quais a agência especializada seja parte; b) disputas que envolvam qualquer funcionário de uma agência especializada que, por motivo de sua posição oficial, goze de imunidade, se a imunidade não houver sido dispensada, de conformidade com as disposições da $22^{\mathrm{a}}$ Seção. 
nidade dos referidos organismos, e eles se obrigariam, por outro, a adotar meios adequados de solução das controvérsias resultantes dos contratos com particulares, estando ambos os entes vinculados, destarte, por obrigações conexas e equivalentes. Silveira defende, pois, diante de uma situação concreta, caberia ao Poder Judiciário, aplicando o princípio da reciprocidade, exigir do organismo internacional a adoção de meios alternativos de solução da controvérsia como condição para o reconhecimento da imunidade. ${ }^{30}$ Acrescenta o autor que, como nenhum tribunal doméstico tem obrigação de conhecer as regras internas das organizações internacionais, a demonstração da existência de tais mecanismos ficaria a cargo delas e, sem ela, o privilégio deveria ser rejeitado. ${ }^{31}$

Silveira avança nessa linha de argumentação ao mencionar até mesmo a possibilidade de penhora das contribuições financeiras do Brasil para com as organizações das quais o país seja membro, em uma espécie de penhora de crédito junto à União.

Ocorre que o afastamento da imunidade de uma organização internacional da qual o Estado do foro é membro por ausência de meios alternativos de solução de controvérsias constituiria uma verdadeira represália contra essa organização por parte de um dos seus Estados-membros e segundo Francisco Rezek não se tem notícia que nenhum país do mundo já tenha adotado uma represália contra as Nações Unidas:

25. Suponha-se, entretanto, e só para argumentar,
que as Nações Unidas deixaram de prover,
conforme pactuado, meios para solução de
controvérsias dessa natureza. A Organização não
é, a rigor, parte em seu próprio tratado constitutivo
- a Carta de São Francisco, firmada por dezenas
de Estados entre os quais o Brasil - nem em
tratados do gênero das Convenções de 1946 e de
1947, concluídos entre os membros da Organização
e a respeito de seu sistema. Sucede que em face
desses tratados a Organização tampouco pode ser
considerada um terceiro, estranho às obrigações
que lhe são assinaladas no texto. Assim pensando,
chegamos a que o hipotético descumprimento de
uma norma do tratado, como a que manda instituir
o foro, seria um ilícito internacional imputável, por
omissão, à própria ONU. Mas para o Brasil, membro
do sistema, este não é um Estado estrangeiro cuja

30 SILVEIRA, Rubens Curado. A Imunidade de Jurisdição dos Organismos Internacionais e os Direitos Humanos. São Paulo: LTr, 2007, p. 108.

31 SILVEIRA, Rubens Curado. A Imunidade de Jurisdição dos Organismos Internacionais e os Direitos Humanos. São Paulo: LTr, 2007, p. 109. eventual conduta ilícita possa ser de todo estranha à nossa própria responsabilidade. As Nações Unidas somos nós, associados a outros cento e noventa Estados não menos soberanos. O ilícito que acaso a Organização cometesse seria, em parte, um ilícito nosso...

26. Abstraindo todas essas singularidades, e raciocinando simplesmente como se a ONU fosse um Estado estrangeiro culpado da violação de norma constante de tratado que o vincula ao Brasil, teríamos de dar o nome correto ao que sucedeu no âmbito da Justiça do Trabalho "em respeito ao princípio da reciprocidade”: uma represália contra a Organização das Nações Unidas. Represália é, em direito internacional, o cometimento consciente de um ato ilícito - qual a violação de norma expressa em tratado - que se entende justificar com a notícia de que a outra parte cometeu, antes, ilícito igual ou equivalente na escala das proporções.

27. Não se tem notícia, em plano global, da adoção de uma represália contra as Nações Unidas. Menos ainda se tem notícia de que esta República, desde sua fundação - ou seu predecessor, o Império do Brasil - tenha um dia incorporado à sua política internacional, a cargo do Governo, a metodologia da represália como reação a algum ilícito de qualquer natureza, cometido por outro Estado soberano. Para dizer o mínimo, é extraordinário que no domínio da Justiça se identifique a iniciativa.

28. Como quer que seja, a represália com que parte da Justiça do Trabalho entende dever punir as Nações Unidas, violando abertamente a imunidade do sistema e comprometendo com isso a responsabilidade internacional da República perante a própria ONU, suas agências especializadas e todos os demais Estados-membros, assenta sobre uma premissa incorreta. Por isso, quando por mais não fosse, não poderia vingar. ${ }^{32}$ (grifo nosso)

Assim, nos casos em que o Estado do foro é membro da organização internacional, o resultado da relativização das imunidades diante da falta de vias alternativas para a solução das controvérsias pode parecer contrário à lógica organizacional. Face a tal situação, como membro do sistema, o Estado do foro não poderia se considerar estranho a essa responsabilidade, como faz quando condena um Estado estrangeiro por tal ilícito. Assim sendo, nessas situações, advogamos pela manutenção das imunidades, deslocando para o Estado do foro o ônus que a priori seria da organização da qual ele é membro.

32 REZEK, Francisco. A Justiça do Brasil ante a Imunidade de Jurisdição das Nações Unidas. In: RAMINA, Larissa; FRIEDRICH, Tatyana Scheila (Orgs.). Direitos Humanos e Jurisdição Internacional. Curitiba: Juruá, 2014, p. 71-72. 


\subsection{O ônus suportado pelo Estado do foro pela manutenção das imunidades das organizações das quais ele é membro na falta de vias alternativas para a solução de controvérsias}

Diferentemente do que acontece quando está em questão uma organização internacional da qual não é membro, nos casos em que o Estado do foro for membro de uma organização internacional titular de imunidade, ele não poderá se considerar estranho à responsabilidade pela denegação de justiça ao particular diante da não promoção de vias alternativas para a solução de controvérsias.

Visando contrabalancear o direito que o particular tem de acessar a justiça para ter a sua controvérsia resolvida e a obrigação que o Estado-membro tem para com a organização internacional, entendemos que, em tais situações, o Estado do foro deveria por um lado, manter as imunidades da organização da qual é membro e por outro, arcar com a responsabilidade face às suas instâncias internas, já que não pode, em nome do cumprimento de suas obrigações internacionais, denegar justiça ao particular.

Nas conclusões finais de sua obra, Madruga Filho ${ }^{33}$ argumenta que, independentemente da análise da existência de vias de recurso alternativas, o ônus suportado pelo particular que teve negado o acesso à jurisdição estatal diante do reconhecimento da imunidade de jurisdição de um sujeito de direito internacional deveria ser distribuído entre toda a sociedade, ou seja, indenizado pelo Estado do foro.

Nesses casos, Madruga Filho ${ }^{34}$ defende a responsabilidade da União pelo débito judicial do Estado estrangeiro. Assim, entende que a União é responsável pela situação de ineficácia da medida executória que deixou a parte brasileira sem receber os valores devidos em razão dos compromissos internacionais que o Estado acordou com outros Estados estrangeiros ou organizações internacionais.

Tal entendimento deve, contudo, ser tomado com parcimônia: caso contrário, a União acabaria se tornando uma pagadora universal de todos os atos afetos aos

33 MADRUGA FILHO, Antenor Pereira. A Renúncia à Imunidade de Jurisdição pelo Estado Brasileiro e o Novo Direito da Imunidade de Jurisdição. Rio de Janeiro: Renovar, 2003, p. 420.

34 MADRUGA FILHO, Antenor Pereira. A Renúncia à Imunidade de Jurisdição pelo Estado Brasileiro e o Novo Direito da Imunidade de Jurisdição. Rio de Janeiro: Renovar, 2003, p. 420.
Estados e organizações internacionais com os quais ela contratou no plano internacional..$^{35}$ Como dissemos, não há necessidade de o Estado do foro se prestar a tal papel se existem vias de execução alternativas perante os foros estrangeiros, o que não impactaria o direito à prestação jurisdicional de maneira desproporcional.

\subsection{Análise do julgamento dos Recursos Extraordinários 578543/MT e 597368/MT proferidos em maio de 2014}

Um recente julgado do Supremo Tribunal Federal que, em maio de 2014, deu provimento a dois recursos extraordinários para reconhecer a imunidade de jurisdição e de execução da Organização das Nações Unidas e do Programa das Nações Unidas para o Desenvolvimento (PNUD) ${ }^{36}$ no que concerne a demandas decorrentes de relações de trabalho. Em ambos os casos, que foram julgados conjuntamente, a $\mathrm{ONU}^{37}$ e a União ${ }^{38}$ questionavam decisões do Tribunal Superior do Trabalho em ações envolvendo trabalhadores brasileiros que, após o término da prestação de serviços ao PNUD, requeriam a completude dos direitos trabalhistas garantidos na legislação brasileira, da anotação da carteira de trabalho ao pagamento de verbas rescisórias. Tendo as ações transitado em julgado, o TST negou provimento, na fase de execução, aos recursos ordinários em ações rescisórias julgadas improcedentes, com fundamento em que a Justiça do Trabalho seria competente para processar e julgar as demandas envolvendo organismos internacionais decorrentes de qualquer relação de trabalho. Por sua vez, a ONU e a União advogavam pela incompetência da Justiça do Trabalho com fundamento em que o PNUD, sendo um programa da ONU, possui

35 MAZZUOLI, Valério de Oliveira. Curso de Direito Internacional Público. 6a ed. São Paulo: Revista dos Tribunais, 2012, p. 567.

36 O Programa das Nações Unidas para o Desenvolvimento PNUD, instituído pela Resolução 2.029 da Assembleia-Geral das Nações Unidas, em 22.11.1965, tem particular importância para os países em desenvolvimento, mas não possui a personalidade jurídica internacional, de que se valem os organismos especializados das Nações Unidas, como a UNESCO, a FAO e a OMS. Trata-se o PNUD, formalmente, como órgão subsidiário da própria ONU, fomentador de políticas de desenvolvimento, diretamente subordinado à Assembleia-Geral e ao Conselho Econômico e Social das Nações Unidas.

37 BRASIL. Supremo Tribunal Federal. Recurso Extraordinário 578543/MT. Relatora: Ellen Gracie. Diário de Justiça Eletrônico, Brasília, 26 maio 2014.

38 BRASIL. Supremo Tribunal Federal. Recurso Extraordinário 597368/MT. Relatora: Ellen Gracie. Diário de Justiça Eletrônico, Brasília, 26 maio 2014. 
regras escritas, quais sejam, a Convenção sobre Privilégios e Imunidades e o Acordo de Assistência Técnica com as Nações Unidas e suas Agências Especializadas, que garantem sua imunidade de jurisdição e de execução.

No Acordo Básico sobre Assistência Técnica para a Organização das Nações Unidas e suas Agências Especializadas, promulgado pelo Decreto 59.308, de 23.09.1966, estão estabelecidos os direitos e obrigações de cada Parte na execução dos projetos de cooperação. É com base nesse diploma de direito internacional que a ONU, por intermédio do PNUD, promove a cooperação com o Brasil em empreendimentos voltados para o desenvolvimento do país. Em seu art. V, 1, a, há a expressa previsão de que o Governo celebrante deverá aplicar, com relação à Organização das Nações Unidas, seus bens, fundos e haveres, a Convenção sobre Privilégios e Imunidades das Nações Unidas.

Por sua vez, tal Convenção promulgada no Brasil pelo Decreto 27.784, de 16.02.1950, prevê, em sua Seção 2, que

A Organização das Nações Unidas, seus bens e haveres, qualquer que seja sua sede ou o seu detentor, gozarão de imunidade de jurisdição, salvo na medida em que a Organização a ela tiver renunciado em determinado caso. Fica, todavia, entendido que a renúncia não pode compreender medidas executivas.

Interessa-nos, nesse caso, o voto de vista em que a Ministra Cármen Lúcia abriu divergência, sendo seguida pelo Ministro Marco Aurélio. Apesar de reconhecer a imunidade da ONU, com fundamento nos tratados internacionais ratificados pelo Brasil, a ministra se mostrou preocupada com a criação de um "limbo jurídico", que não garantiria ao cidadão brasileiro contratado por essas organizações direitos sociais fundamentais, entre os quais o de acesso à justiça. Por tais razões, seu voto foi no sentido de responsabilizar a União pelos direitos trabalhistas decorrentes do acordo de cooperação técnica com o PNUD, que previa expressamente que o Estado custearia, entre outras coisas, os serviços locais de pessoal técnico e administrativo, de secretaria e de intérpretes. Para ela, isso permitiria conciliar a imunidade da jurisdição da ONU e o direito do cidadão brasileiro de receber direitos trabalhistas já reconhecidos em todas as instâncias da Justiça do Trabalho em ações transitadas em julgado.

Contudo, a maioria dos ministros seguiu o voto da Ministra Ellen Gracie, que se posicionou contra as deci- sões do TST que obrigaram o PNUD ao pagamento de direitos trabalhistas por ocasião do encerramento dos contratos de trabalho. O entendimento majoritário foi no sentido de que tais decisões violavam as obrigações internacionais que foram convencionadas pelo Brasil. ${ }^{39}$ Os ministros que seguiram o voto da relatora ainda destacaram que os funcionários que contrataram com a ONU, quando o fizeram, já estavam cientes de que teriam que submeter eventuais litígios trabalhistas aos seus tribunais administrativos, e não à jurisdição brasileira.

Em consonância com o defendido neste artigo, entendemos que a existência de tais tribunais afasta os questionamentos apresentados pela Ministra Carmen Lúcia acerca de uma possível ofensa ao direito de acesso à jurisdição dos litigantes, uma vez que eles terão a sua demanda julgada por um órgão de solução de controvérsias criado pela própria organização para julgar tal tipo de demanda.

Foi esse, inclusive, o entendimento do ex-Ministro Francisco Rezek em parecer datado de 20 de julho de 2007, juntado ao processo quando este se encontrava no TST:

No quadro dos programas da Organização ou de suas agências, quem quer que preste serviços às Nações Unidas ingressa conscientemente em regime determinado pela ordem jurídica do sistema, pouco importando que a sede de trabalho seja Nova York, Istambul, Brasília ou Nairóbi, e que a função seja a do vigilante, a do técnico, a do especialista, a do Secretário-Geral ou a do juiz

39 DIREITO INTERNACIONAL PÚBLICO. DIREITO CONSTITUCIONAL. IMUNIDADE DE JURISDIÇÃO. ORGANIZAÇÃO DAS NAÇÕES UNIDAS (ONU). PROGRAMA DAS NAÇÕES UNIDAS PARA O DESENVOLVIMENTO (ONU/ PNUD). RECLAMAÇÃO TRABALHISTA. CONVENÇÃO SOBRE PRIVILÉGIOS E IMUNIDADES DAS NAÇÕES UNIDAS (DECRETO 27.784/1950). APLICAÇÃO. 1. Segundo estabelece a "Convenção sobre Privilégios e Imunidades das Nações Unidas", promulgada no Brasil pelo Decreto 27.784, de 16 de fevereiro de 1950, “A Organização das Nações Unidas, seus bens e haveres, qualquer que seja seu detentor, gozarão de imunidade de jurisdição, salvo na medida em que a Organização a ela tiver renunciado em determinado caso. Fica, todavia, entendido que a renúncia não pode compreender medidas executivas". 2. Esse preceito normativo, que, no direito interno, tem natureza equivalente à das leis ordinárias, aplica-se também às demandas de natureza trabalhista. 3. Recurso extraordinário provido. BRASIL. Supremo Tribunal Federal. Recurso Extraordinário 578543/MT. Relatora: Ellen Gracie. Diário de Justiça Eletrônico, Brasília, 26 maio 2014. No mesmo sentido, vide BRASIL. Supremo Tribunal Federal. Agravo Regimental no Agravo de Instrumento 744777/ DF. Relator: Gilmar Mender. Diário de Justiça Eletrônico, Brasília, 21 jun. 2013. 
da Corte Internacional de Justiça. Esse regime, quando não proporciona ação direta ao funcionário acaso descontente no Tribunal Administrativo das Nações Unidas, prescreve a arbitragem como meio de solução do eventual litígio, possível sempre - e já experimentado na prática - o acesso ao Tribunal para que este garanta a realização da arbitragem. ${ }^{40}$

E completa:

Nas espécies em exame, contudo, qualquer ressentimento diante da imunidade das Nações Unidas ou de suas agências seria um perfeito despropósito, seja porque não faltam mecanismos de solução de controvérsias previstos pelo sistema organizacional e pelos contratos celebrados em nosso meio, seja porque a própria Organização nunca foi a usuária final dos serviços contratados, prestados estes, sempre, aos projetos de desenvolvimento acordados com o Brasil e quase sempre geridos por órgãos da administração pública brasileira. $^{41}$

Não podemos negar, contudo, estarmos diante de uma situação peculiar no caso em questão. Nele, poderíamos entender que o PNUD teria atuado como intermediador de mão de obra para a Administração Pública, o que, de certa forma, implicaria uma responsabilidade subsidiária do Estado pelo pagamento dos valores devidos aos funcionários do programa das Nações Unidas. ${ }^{42}$

Em seu estudo, Silveira faz menção a uma ação civil pública ajuizada pelo Ministério Público do Trabalho em setembro de 2001 contra a União e seis organizações internacionais. ${ }^{43} \mathrm{O}$ objeto da demanda era arguição de desrespeito à regra constitucional do concurso público por meio da contratação de "consultores técnicos" pelas organizações internacionais para a prestação de serviços nos Ministérios. Essa prática, segundo o Minis-

40 REZEK, Francisco. A Justiça do Brasil ante a Imunidade de Jurisdição das Nações Unidas. In: RAMINA, Larissa; FRIEDRICH, Tatyana Scheila (Orgs.). Direitos Humanos e Jurisdição Internacional. Curitiba: Juruá, 2014, p. 68-69.

41 REZEK, Francisco. A Justiça do Brasil ante a Imunidade de Jurisdição das Nações Unidas. In: RAMINA, Larissa; FRIEDRICH, Tatyana Scheila (Orgs.). Direitos Humanos e Jurisdição Internacional. Curitiba: Juruá, 2014, p. 76.

42 SILVEIRA, Rubens Curado. A Imunidade de Jurisdição dos Organismos Internacionais e os Direitos Humanos. São Paulo: LTr, 2007, p. 162-163.

43 BRASIL. Tribunal Regional do Trabalho. $15^{\text {a }}$ Vara do Trabalho de Brasília. Ação Civil Pública n. 1.044. Brasíia, 7 jun. 2002. As organizações internacionais demandadas foram a Organização das Nações Unidas para Agricultura e Alimentação (FAO); a Faculdade Latino-Americana de Ciências Sociais (FLACSO); o Instituto Interamericano de Cooperação para a Agricultura (IICA); a Organização Internacional do Trabalho (OIT); a Organização das Nações Unidas para a Educação, Ciência e Cultura (UNESCO) e o Programa das Nações Unidas para o Desenvolvimento (PNUD). tério Público, resultou na contratação de mais de oito mil trabalhadores sem que concurso algum tivesse sido realizado.

Em situações como essas, a Administração Pública tem se portado como uma grande tomadora dos serviços e, portanto, beneficiária final do labor dos trabalhadores. ${ }^{44}$ Essa parceria entre o Estado e a organização internacional não deixa de ser, em sua essência, uma terceirização de serviços, afinal, em vez de executar seus projetos por meio de seus servidores públicos, a Administração prefere transferir o trabalho para um ente internacional. Nesse caso, conforme dispõe a Súmula 331 do $\operatorname{TST}^{45}$, reconhecida a terceirização da mão de obra, o tomador deve ser responsabilizado subsidiariamente em casos de inadimplência do prestador dos serviços. Em função disso, mesmo que reconhecida a imunidade de execução dos bens da organização internacional, o reclamante poderá pleitear a execução dos bens do tomador dos serviços, qual seja, o Estado brasileiro.

Contudo, entendemos que, para os casos em que a União não seja tomadora do serviço, ela, ainda sim,

44 Ver, por exemplo BRASIL. Tribunal Regional do Trabalho.

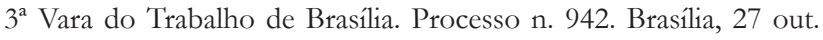
2004. Nesta ação, o reclamante foi contratado como "consultor técnico" do PNUD para prestar serviços de digitalização dentro do Instituto de Pesquisa Econômica Aplicada - IPEA, fundação pública subordinada ao Ministério do Planejamento, órgão executor do "Programa Rede de Pesquisa e Desenvolvimento de Políticas Públicas."; Vide também BRASIL. Tribunal Regional do Trabalho. $3^{a}$ Vara do Trabalho de Brasília. Processo n. 00048-2004-000-10-005 MS. Relatora: Heloísa Pinto Marques. Diário Eletrônico da Justiça do Trabalho, Brasília, 26 nov. 2004. Nesse caso, a reclamante foi formalmente contratada pela UNESCO para prestar serviços de digitação no Centro de Processamento da Fundação Hospitalar do Distrito Federal.

45 BRASIL Tribunal Superior do Trabalho. Súmula 331. Diário Eletrônico da Justiça do Trabalho, Brasília, 27 maio 2011. CONTRATO DE PRESTAÇÃO DE SERVIÇOS. LEGALIDADE. I A contratação de trabalhadores por empresa interposta é ilegal, formando-se o vínculo diretamente com o tomador dos serviços, salvo no caso de trabalho temporário (Lei n. 6.019, de 3.1.1974). II- A contratação irregular de trabalhador, mediante empresa interposta, não gera vínculo de emprego com os órgãos da administração pública direta, indireta ou fundacional (art. 37, II, da CF/1988). III- Não forma vínculo de emprego com o tomador a contratação de serviços de vigilância (Lei n. 7.102, de 20.6.1983) e de conservação e limpeza, bem como a de serviços especializados ligados à atividade-meio do tomador, desde que inexistente a pessoalidade e a subordinação direta. IV - O inadimplemento das obrigações trabalhistas, por parte do empregador, implica a responsabilidade subsidiária do tomador dos serviços, quanto àquelas obrigações, inclusive quanto aos órgãos da administração direta, das autarquias, das fundações públicas, das empresas públicas e das sociedades de economia mista, desde que hajam participado da relação processual e constem também do título executivo judicial (art. 71 da Lei n. 8.666, de 21.6.1993). 
ela poderia ser responsabilizada, desde que o respeito à imunidade de jurisdição da organização internacional da qual o Estado é membro venha implicar denegação de justiça ao particular.

Nessas situações, não seria justo que o particular fosse privado do acesso à justiça e suportasse sozinho o prejuízo decorrente de uma obrigação do Estado, a saber, a de obedecer às obrigações internacionais para com a organização da qual ele é membro. A observação dessa obrigação converte-se em benefício para toda a coletividade.

Assim, diante da impossibilidade de se valer de uma via de recurso alternativa para o processamento do feito e da indisposição do Estado do foro de afastar a imunidade da organização internacional da qual ele mesmo é membro, em respeito ao direito de acesso à justiça, entendemos que o Estado do foro deveria responder perante as suas instâncias judiciais pelos ilícitos praticados pela organização internacional em questão.

Contudo, quando o sujeito de direito internacional é uma organização internacional da qual o Estado do foro não é membro, não haveria razões para não relativizar as imunidades das quais eles venham a gozar diante da falta de indicação de vias alternativas para a solução da controvérsia. Nesse caso, ao Estado do foro seria possibilitada a relativização de sua obrigação de garantir a imunidade para que não tivesse que responder em juízo em nome de uma organização internacional que não se conformou aos ditames do princípio de direito de acesso à justiça.

\section{Considerações finais}

Diante do que foi exposto, é possível concluir que as imunidades das organizações internacionais não são contrárias ao direito de acesso à justiça, dado que elas não resultam na impunidade da organização mas apenas direcionam a demanda para julgamento em um foro mais adequado que tenha sido disponibilizado pela organização internacional.

Dessa forma, a única possibilidade de relativização da regra das imunidades em nome do respeito ao direito de acesso à justiça ocorreria nos casos de inexistência de foro alternativo possível para a resolução da controvérsia, caso em que a manutenção do benefício das imu- nidades teria por consequência a flagrante violação do direito à jurisdição.

Além da comprovação da existência de meios alternativos para a solução das controvérsias, caberia aos tribunais estatais verificar se esses mecanismos atendem, razoavelmente, às garantias mínimas do direito à jurisdição, tais como a independência e a imparcialidade, sob pena de eles servirem de mero subterfúgio à perpetuação do privilégio.

Contudo, nos casos em que o Estado do foro seja membro da organização internacional, o resultado da relativização das imunidades diante da falta de vias alternativas para a solução das controvérsias pode parecer contrário à lógica organizacional, pois ele constituiria uma verdadeira represália contra essa organização aplicada por um dos seus Estados-membros.

Entendemos que, como membro do sistema, o Estado do foro não poderia se declarar estranho a essa responsabilidade, como faz quando condena um Estado estrangeiro por tal ilícito. Face a tal situação, defendemos a manutenção das imunidades organizacionais, deslocando para o Estado do foro o ônus que a priori seria da organização da qual ele é membro.

\section{REFERÊNCIAS BIBLIOGRÁFICAS}

ABREU, Patrícia Maria Lara; RAPOSO, Rodrigo Otávio Bastos Silva. Imunidade de jurisdição do Estado e reparação civil pela prática de tortura: o caso Zahra Kazemi v. República Islâmica do Irã. Revista de Direito Internacional, Brasília, v. 11, n. 2, p. 412-434, 2014.

CANOTILHO, José Joaquim Gomes. Direito Constitucional, 6a edição, Coimbra: Almedina, 1993.

GAILLARD, Emmanuel; PINGEL-LENUZZA, Isabelle. International Organisations and Immunity from Jurisdiction: To restrict or to bypass. International and Comparative Law Quarterly, Oxford, v. 51, n. 1, p. 1-15, jan. 2002.

GERSTER, Michael; ROTENBERG, Dirk. Article 105. In: SIMMA, Bruno; KHAN, Daniel-Esrasmus (Orgs.). The Charter of the United Nations: A Commentary. Oxford: Oxford University Press, 1995.

MADRUGA FILHO, Antenor Pereira. A Renúncia 
à Imunidade de Jurisdição pelo Estado Brasileiro e o Novo Direito da Imunidade de Jurisdição. Rio de Janeiro: Renovar, 2003.

MAZZUOLI, Valério de Oliveira. Curso de Direito Internacional Público. 6a ed. São Paulo: Revista dos Tribunais, 2012.

REINISCH, August. International Organizations Before National Courts. Cambridge: Cambridge University Press, 2000.

REINISCH, August.; WEBER, Ulf Andreas. In the Shawdow of Waite and Kennedy: The Jurisdicional Immunity of International Organizations, The Individual's Right of Acces to the Courts and Administrative Tribunals as Alternative means of Dispute Settlement. International Organization Law Review, Leiden, v. 1, n. 1, p. 59-110, 2004.

REZEK, Francisco. A Justiça do Brasil ante a Imunidade de Jurisdição das Nações Unidas. In: RAMINA, Larissa; FRIEDRICH, Tatyana Scheila (Orgs.). Direitos Humanos e Jurisdição Internacional. Curitiba: Juruá, 2014, p. 65-76.

REZEK, Francisco. Direito Internacional Público: Curso Elementar. São Paulo: Saraiva, 2010.

SILVEIRA, Rubens Curado. A Imunidade de Jurisdição dos Organismos Internacionais e os Direitos Humanos. São Paulo: LTr, 2007.

VERHOEVEN, Joe. Considérations sur ce qui est commun: cour général de droit international public. Recueil des cours, La Haye, v. 334, p. 9-434, 2008.

VERHOEVEN, Joe. Immunités de Jurisdiction ou d'éxécution, alternatives raisonnables et jurisprudence belge. In: KOHEN, Marcelo Gustavo; KOLB, Robert; DOMINICÉ, Christian (Orgs.). Perspectives du droit international au 21ème siècle: liber amicorum Professor Christian Dominicé. Leiden: Nijhoff, 2012, p. 147-160.

VERHOEVEN, Joe. Sur les relations entre immunités et "jus cogens", à la lumière de l'arrêt Allemagne-Italie du février 2012. In: Unité et diversité du droit international: écrits en l'honneur du professeur Pierre-Marie Dupuy. Bruxelles: Martinus Nijhoff Publishers, 2014, p. 527-538.

WATT, Horatia Muir. Une perspective "internationaliste-privatiste". In: VERHOEVEN, Joe (Org.) Le droit international des immunités: contestation ou consolidation? Bruxelles: Larcier, 2004, p. 265-274.

WELLENS, Karel. Remedies Against International Organisations: Basic Issues. Cambridge: Cambridge University Press, 2002. 
Para publicar na Revista de Direito Internacional, acesse o endereço eletrônico www.rdi.uniceub.br ou www.brazilianjournal.org.

Observe as normas de publicação, para facilitar e agilizar o trabalho de edição. 